\title{
The thickness and structural characteristics of the crust across Tibetan plateau from active-sources seismic profiles*
}

\author{
Qiusheng Li ${ }^{1,2, \uparrow}$ Rui Gao ${ }^{1,2}$ Zhanwu Lu ${ }^{1,2}$ Ye Guan ${ }^{1,2}$ Jisheng Zhang ${ }^{1,2}$ \\ Pengwu Li ${ }^{1,2}$ Haiyan Wang ${ }^{1,2}$ Rizheng $\mathrm{He}^{1,2}$ and Marianne Karplus ${ }^{3}$
}

\author{
${ }^{1}$ Lithosphere Research Center, Institute of Geology, Chinese Academy of Geology Science,Beijing 100037, China \\ ${ }^{2}$ Earthprobe and Geodynamics Open Laboratory of Chinese Academy of Geology Science, Beijing 100037, China \\ ${ }^{3}$ Crustal Geophysics Group, Stanford University, Stanford CA 94305, USA
}

\begin{abstract}
The Tibetan plateau as one of the youngest orogen on the Earth was considered as the result of continent-continent collision between the Eurasian and Indian plates. The thickness and structure of the crust beneath Tibetan plateau is essential to understand deformation behavior of the plateau. Active-source seismic profiling is most available geophysical method for imaging the structure of the continental crust. The results from more than 25 active-sources seismic profiles carried out in the past twenty years were reviewed in this article. A preliminary cross crustal pattern of the Tibetan Plateau was presented and discussed. The Moho discontinuity buries at the range of $60-80 \mathrm{~km}$ on average and have steep ramps located roughly beneath the sutures that are compatible with the successive stacking/accretion of the former Cenozoic blocks northeastward. The deepest Moho (near $80 \mathrm{~km}$ ) appears closely near IYS and the crustal scale thrust system beneath southern margin of Tibetan plateau suggests strong dependence on collision and non-distributed deformation there. However, the $\sim 20 \mathrm{~km}$ order of Moho offsets hardly reappears in the inline section across northern Tibetan plateau. Without a universally accepted, convincing dynamic explanation model accommodated the all of the facts seen in controlled seismic sections, but vertical thickening and northeastern shorten of the crust is quite evident and interpretable to a certain extent as the result of continent-continent collision. Simultaneously, weak geophysical signature of the BNS suggests that convergence has been accommodated perhaps partially through pure-shear thickening accompanied by removal of lower crustal material by lateral escape. Recent years the result of Moho with $\sim 7 \mathrm{~km}$ offset and long extend in south-dip angle beneath the east Kunlun orogen and a grand thrust fault at the northern margin of Qilian orogen has attract more attention to action from the northern blocks. The broad lower-velocity area in the upper-middle crust of the Lhasa block was once considered as resulted from partially melted rocks. However the low normal $v_{\mathrm{P}} / v_{\mathrm{S}}$ ratio and the Moho stepwise rise fail to support significant partial melting in the middle-lower crust of the central-northern Tibetan plateau. Furthermore, the lower-velocity of crust occasionally disappears, and/or local thinned exhibits their non-stationary spatial distribution.
\end{abstract}

Key words: crustal structure, crustal thickness, active-sources seismic, Tibetan plateau CLC number: P313.2 Document code: A

\section{Introduction}

The Tibetan plateau, one of the highest, largest, and youngest orogens on Earth, was created by continent-continent collision between the Eurasian plate and the northward-moving Indian plate. It is therefore widely considered as an optimal field laboratory to

\footnotetext{
* Received 12 August 2008; accepted in revised form 7 November 2008; published 10 February 2009.

• Corresponding author. e-mail: liqiusheng@cags.net.cn.
}

study continental dynamics and an ideal site to correlate geophysics survey results with geological tectonics.

The thickness and structure of the crust and status of the upper mantle of the Tibetan plateau are key parameters to understand its collision behavior and deformation history. High resolution (active source seismic profiling near vertical reflection: $\sim 10-100 \mathrm{~m}$; wide angle reflection/refraction: $\sim 1-10 \mathrm{~km}$ ) allows imaging of the structure of the continental crust. Since the 1950s scientists have made much effort to probe the Tibetan Plateau crust with wide-angle reflection/refraction pro- 
filing and near vertical reflection profiling. More than 25 active-source seismic profiles [deep seismic sounding (DSS), including wide-angle seismic reflection and refraction profiles, profiles and near vertical reflection profile] with a total length of $12600 \mathrm{~km}$ have been carried out around the Tibetan Plateau. In this paper the authors give a review of advancements over the past thirty years, focusing on the region of $26^{\circ} \mathrm{N}-40^{\circ} \mathrm{N}, 76^{\circ} \mathrm{E}-106^{\circ} \mathrm{E}$, summarizing the results on thickness and structure of the crust beneath Tibetan Plateau to try relating the deep structure to its deformation mechanism.

\section{Distribution of active-sources seismic profiles}

Active-source seismic profiles have been used to study the crustal structure of Tibetan plateau for 50 years since Dr. Zeng and his group first carried out a seismic reflection test in the Qaidam basin in 1958 (Zeng and Gan, 1961; Teng et al, 1974). By 2007 more than 25 active-source seismic profiles (deep seismic sounding (DSS) and near vertical reflection profiles) with a total length of $12600 \mathrm{~km}$ have covered most of the Tibetan plateau in a sparse, irregular net with the exception of the northern part (Figure 1).

A $460 \mathrm{~km}$-long $\mathrm{N}-\mathrm{S}$-stretching profile along the Yadong-Damxung rift carried out by Chinese Academy of Sciences (CAS) in 1977 (Institute of Geophysics, Chinese Academy of Sciences, 1981) stands out as one of the notable marks in the progress of modern seismic technique applied to research on the Tibetan plateau. A Sino-French cooperative project (entitled "Formation and Evolution of Himalaya Geological Structures, Crust

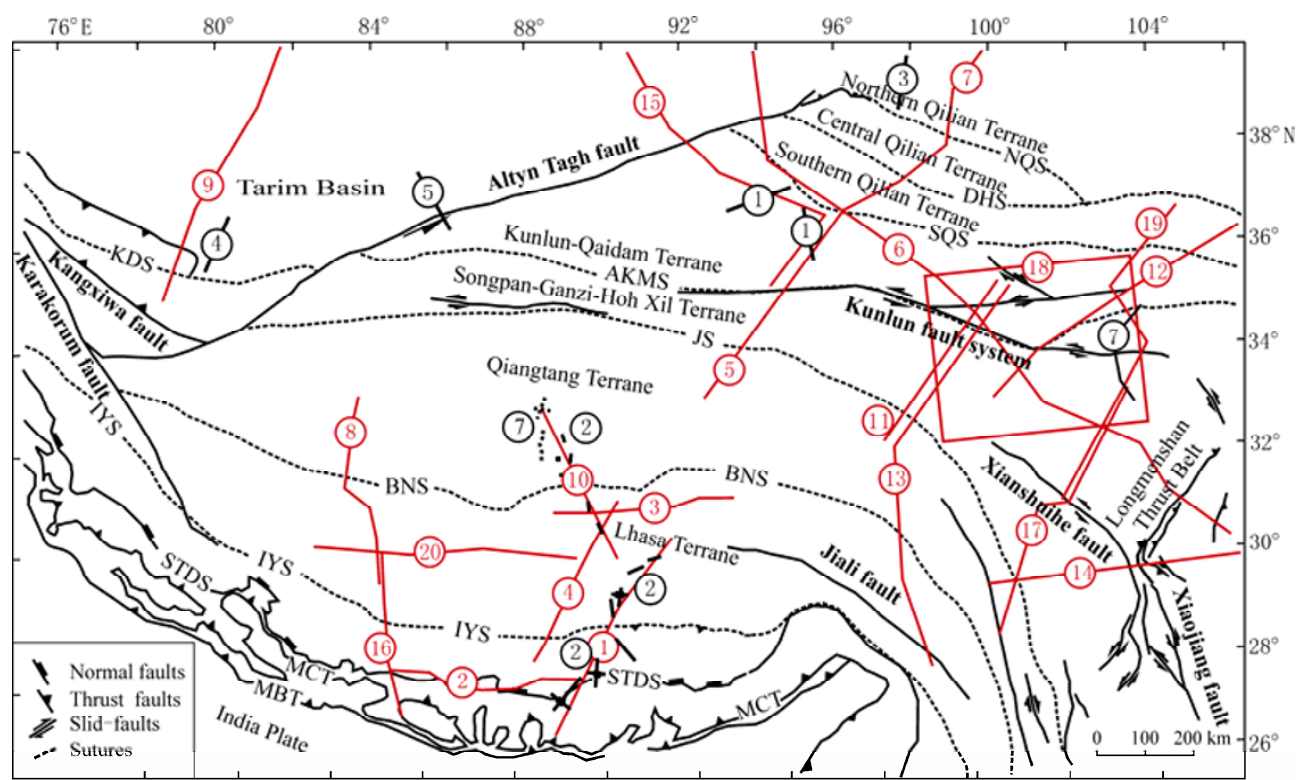

Figure 1 The active-source seismic profile in the Tibetan plateau (up to 2008). Tectonic settings (Yin and Mark, 2000): IYS: Indus-Yalu suture; BNS: Bangong-Nujiang suture; JS: Jinsha suture; AKMS: AyimaqiKunlun-Mutztagh suture; SQS: South Qilian suture; DHS: Danghe Nan Shan suture; NQS: North Qilian suture; KS: Kudi suture; STDS: South Tibet Detachment System; MCT: Main Central Thrust; MBT: Main Boundary Thrust. DSS profiles numbering (red): 1. Yadong-Damxung (Institute of Geophysics, Chinese Earthquake Administration, 1981); 2. Paikü Co-Puma Yumco (Teng et al, 1983;); 3. Siling Co-Y'angamdo (Teng et al, 1985); 4. Gala-Amdo (Xiong et al, 1985); 5. Tuotuohe-Golmud (Lu and Chen, 1987); 6. Aksay-Huashixia-Jianyang (Xu et al, 1993; Cui et al, 1996); 7. Golmud-Ejin Qi (Cui et al, 1995); 8. Cuoqin-Sangehu (Xiong and Liu, 1997); 9. Quanshuigou-Dushanzi (Li et al, 2001); 10. Deqen (Nam Tso)-Longwei Tso (Zhao et al, 2001); 11. Gonghe-Yushu (Wang and Qian, 2000; Vergne et al, 2002); 12. Maqin-Lanzhou-Jingbian (Li et al, 2002); 13. Gonghe-Yushu-Xiachayu (Zhang et al, 2002a); 14. Batang-Zizhong (Wang et al, 2003a); 15. Golmud-Da Qaidam-Mangya-Ruoqiang (Zhao et al, 2001, 2003, 2006); 16. Zham-Coqen (Liu et al, 2004); 17. Benzilan-Tangke (Wang et al, 2003b); 18. 3D profile on eastern Kunlun (Zhang et al, symposium report, 2002); 19. Ma'erkang-Gulang (Zhang et al, 2008); 20. Eastern Silin Co-Western Coqen (Zhang et al, symposium report, 2004). Near vertical seismic profiling numbering (black): 1. Yuka-Gansen and Golmud-Da Qaidam (Zeng et al, 1961); 2.Profiles of INDEPTH Project I-III (solid line segment) (Zhao et al, 1993, 1997); 3. Diaodaban-Huahai (Wu et al, 1995); 4. West Kunlun-Tarim (Gao et al, 2000b); 5. Altyn-Tarim (Gao et al, 2000a); 6. Tangke-Hezuo (Gao et al, 2005a); 7. The experiment of seismic acquisition method for petroleum and natural gas exploration (dot line) (Gao et al, 2005b). 
and Upper Mantle") (Zhao et al, 1997) during 1980-1982 applied the most advanced DSS technology of its time. Two in-line transects, a profile along structural strike located in the Tethyan Himalayan terrane and Lhasa block and a fan-recording profile across the India-Yalung Zangbo suture, are still widely cited today. Most later profiles cross the sutures are from north to south (Lu and Chen, 1987; Cui et al, 1995; Xiong and Liu, 1997; Zhao et al, 2001, Liu et al, 2004; Vergne et al, 2002, Wang and Qian, 2000; Zhang et al, symposium report, 2002) except the profile Eastern Silin Co-Western Coqen (Zhang et al, symposium report, 2004).

Several of the early profiles that follow the highway from Lhasa to Golmud have been compiled into Yadong-Golmud GGT (Wu et al, 1991). Scientists continue to debate some of the results, such as the role of the northeastward rifts (e.g., Yadong-Gulu rift).

In order to trace the lateral variation in crustal structure along the Indus-Yarlung (Tsangpo) Suture while avoiding the rift influence, Chinese geophysicists designed and collected the profiles in 1994 (Xiong and Liu, 1997, No.8 in Figure 1) and 2001 (Liu et al, 2004, No.16 in Figure 1) $200 \mathrm{~km}$ west to Yadong-Gulu rift across IYS along the route from Nielamu-Saga-Coqen.

In recent decades more attention has been paid to the relationship and interaction between the plateau and its neighboring blocks. Some profiles extended from the Tarim, Yangtze or North China blocks across the eastern or northern margin of the plateau (Wang and Qian, 2000, Wang et al, 2003a, b; Li et al, 2001; 2002; Vergne et al, 2002, Zhang, personal communication, 2004, Zhang et al, 2008 ). The 3D survey system has been attempted in the eastern plateau (Zhang et al, symposium report, 2002). Our main knowledge regarding the structure of the crust and upper mantle beneath the Tibetan Plateau is from the DSS profiles covering most of the Tibetan Plateau except the northwestern area.

Comparatively, the near vertical reflection profiles cover a less area than DSS profiles and are sporadically distributed in the south, east and surroundings of the plateau.

In the early of $1990 \mathrm{~s}$, the near-vertical seismic reflection method with multiple coverage, successfully used by COCORP to probe the North American continental crust and first brought to the Tibetan plateau by Project INDEPTH (abbreviation of "International Deep Profiling of Tibet and the Himalaya") aimed at the deep structure of the active continent-continent collision zone.

INDEPTH I-III has been completed and its stage IV is in progress. The INDEPTH I (1992 1994) and II (1994-1996) focus on near-vertical seismic profiling. The first $100 \mathrm{~km}$ test profile in the Himalayan was finished in 1992 (stage I) to confirm that seismic waves generated from active sources were able to penetrate the $80 \mathrm{~km}$ crust of the Tibetan Plateau (Zhao et al, 1993). Then $250 \mathrm{~km}$ of profiling (the black short line in Figure 1) was collected across the IYS from 1994-1996 (stage II) to determine the extent of Indian lithosphere subducting beneath the IYS and Lhasa block (Nelson et al, 1996; Zhao et al, 1997). The principal objectives of INDEPTH III (1998-2001) are to elucidate the mechanism of crustal shortening and thickening in the interior of the plateau through DSS profiling along a $400 \mathrm{~km}$ long NNW-SSE profile from Lhasa block to the central Qiangtang terrane at about $89.5^{\circ} \mathrm{E}$, crossing the Bangong-Nujiang suture (BNS) (Zhao et al, 2001). A short-period, 60 channel geometrics system with vertical component geophones was brought there for near-vertical acquisition experiment, four in-line and one cross-line profiles of small shots (charge size $2 \mathrm{~kg}$ to $50 \mathrm{~kg}$ ) were obtained (Haines et al, 2003; Ross et al, 2004 ). During stage IV, a $280 \mathrm{~km}$ wide-angle seismic profile was acquired with about $50 \mathrm{~km}$ of near vertical profiling across east Kunlun Mountains (the project is in progress) to determine intracontinental subduction and the crustal scale faults proposed by predecessors recent year (Zhu and Helmberger, 1998; Wittlinger et al, 1998; Kind et al, 2002).

At the same time of INDEPTH, a number of near-vertical profiles in the eastern part or across the mountain-basin junction around the northern and eastern margin of the plateau have been finished independently by Chinese geophysicists (Gao et al, 2000 a, b, 2005a). To improving methods of acquisition and data process petroleum seismic exploration, a total of $200 \mathrm{~km}$ of experiment profiles have been completed by the Chinese Geological Survey Bureau in 2004-2008 (Gao et al, 2005b).

Although the total length was only about 10 percent of DSS (about $1300 \mathrm{~km}$ ) due to high cost, the fine structure of the crust imaged by near-vertical profiles plays a crucial role in elucidating the dynamic mechanisms of deformation caused by continent-continent collision. We believe it will be used more widely to survey the crust of the Tibetan plateau in the future. 


\section{Crustal thickness variations across Tibet}

DSS profiling often records a strong reflection wave group Pm (a critical and/or over-critical reflection phase of $\mathrm{P}$ wave from the boundary of crust and upper mantle) since DSS profiling is more sensitive to vertical velocity variation. Analyzing and correlating $\mathrm{Pm}$ travel-time curves through inverse/forward calculation enables the estimation of Moho depths even in the invalid regions.

Large-scale surface wave inversion, P-wave tomography and teleseismic receiver functions gave Moho depths of $>60 \mathrm{~km}$ on average that roughly mirror the surface of the plateau with larger crustal thicknesses (15-20 km larger than around blocks) under higher elevation regions (Chen and Zeng, 1985; Zhuang et al, 1992;
Mayakovsky, 1996; Lü et al, 1996; Wu et al, 1998; Griot et al, 1998; Wu and Zeng, 1998 ; Kind et al, 2002; Zhao et al, 2004; Pelkum et al, 2005 ), but that not accurate enough (thickness) and without detail (structure ) imaged by passive seismic profiling due to sparse spatial sampling and lower natural frequency, only denser active-source profiles allow these thicknesses to be corroborated and constrained in greater detail.

Unexpectedly, the largest Moho depth appear not in the central of the plateau but in the vicinity of IYS with a value range of $70-80 \mathrm{~km}$ from that Moho stepwise decreases both to the south (beneath Himalaya) and to the north (Teng et al, 1983; Hirn et al, 1984a, b; Zhao et al, 1993; Kind et al, 1996; Yuan et al, 1997; Tapponnier et al, 2001; Galvé et al, 2002; Vergne et al, 2002) (Figure 2).
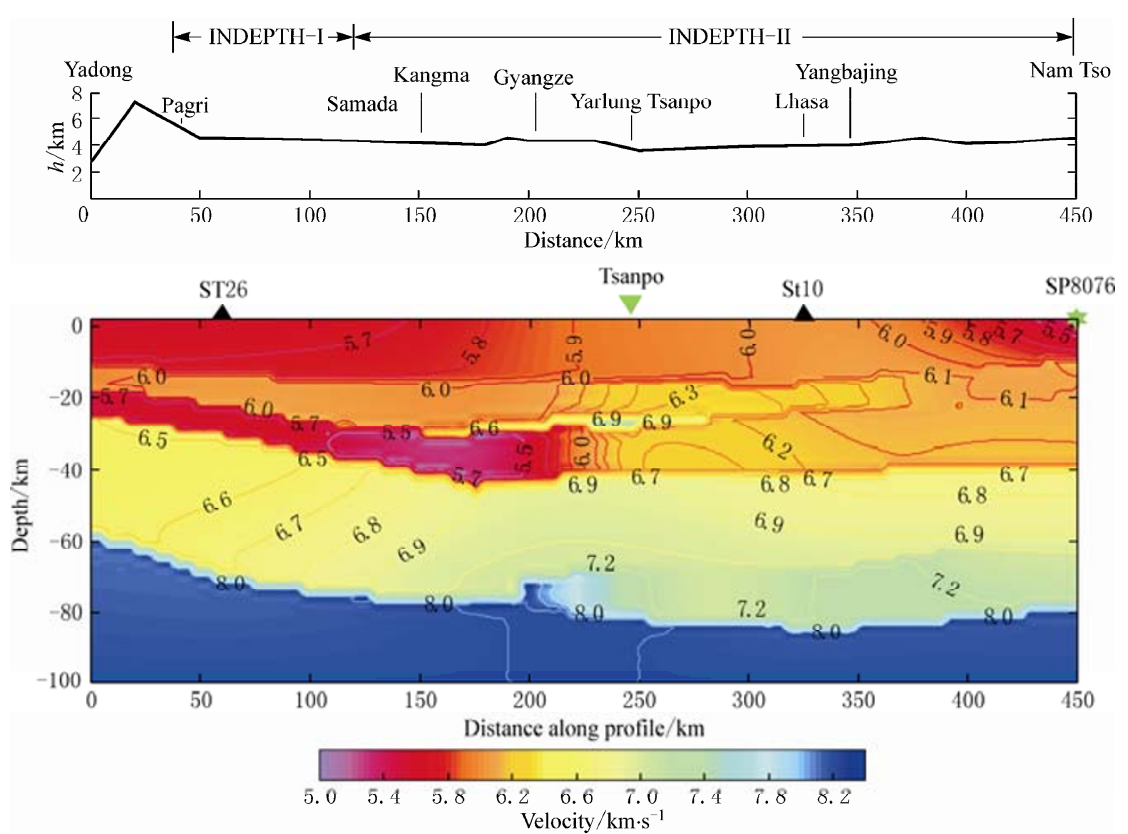

Figure 2 The velocity (P wave )-depth sections from INDEPTH 1, 2 piggyback-wide angle data The Indus-Yarlung Tsanpo Suture is marked as "Tsanpo" in the section.

The Moho depth beneath the Himalayan Terrane has been well constrained by DSS, near vertical, and passive source seismic profiling (Teng et al, 1983; Hirn et al, 1984 a, b; Zhao et al, 1993; Kind et al, 1996; Yuan et al, 1997; Zeng et al, 2000; Zhang et al, 2002b). From the IYS to the southern margin of the plateau, the Moho rapidly rises from $\sim 80 \mathrm{~km}$ (under Tethyan Himalaya very close to IYS) to $<40 \mathrm{~km}$ (under Northern India). Across IYS, beneath the southern part of Lhasa block, the Moho depth had been debated by some scientist between $55 \mathrm{~km}$ and $70 \mathrm{~km}$ (Hirn et al, 1984; Xiong et al, 1985). Recent data (Zhao et al, 2001; Liu et al, 2004;
Zhang, personal communication, 2004) supports a depth of $\sim 70 \mathrm{~km}$ (Sapin et al, 1985) even locally deep to $\sim 80$ $\mathrm{km}$ beneath Yadong-Gulu graben/rift and its northern extension (Zhang et al, 2001) if the crust/mantle mix zone is considered part of the crust.

Due to poor coverage, Moho depth beneath the central Qiangtang block is still unclear with only its southern and the northern part constrained respectively by Nam Tso-Longwei Tso profile of INDEPTH III at the depth of $(60 \pm 5) \mathrm{km}$ (Zhao et al, 2001)and Tuotuohe-Golmud profile ( $\mathrm{Li}, 2004 \mathrm{~b})$ at the depth of $70 \mathrm{~km}$ (Figure 3). 
The crustal thickness of the northeastern region of Tibetan plateau is determined by three profiles (DSS profile 5, 11, and 13 in Figure 1), acquired respectively in 1983 (Lu and Chen, 1987, 1990), 1998 (Wang and Qian, 2000; Galvé et al, 2002 a) and 2000 (Zhang et al, 2002 a). These don't appear to be completely consistent with each other or with the passive seismic (Ding et al, 1992). Scientists have tended to accept that the Moho depth varies in a stepwise fashion, from $70 \mathrm{~km}$ (the northern edge of Qiangtang block, under Jinsha Suture) through Bayan Har and east Kunlun orogen belt (60-70 $\mathrm{km})$ continually to (52 \pm 2$) \mathrm{km}$ (Qaidam Basin) (Tapponnier et al, 2001; Galvé et al, 2002a; Vergne et al, 2002). That geometrical image has been built through reinterpretation of the Tuotuohe-Golmud profile and the southern part of the Golmud-Ejin profile (Figure 3) (Li et al, 2004). The geometrical feature is supported by a $500 \mathrm{~km}$ east profile (DSS profile 11 in Figure 1) (Vergne et al, 2002). The geometrical characteristics seem to suggest the Jinsha river suture plays an important role in the formation and evolution of the northern Tibetan Plateau. It is probably the main suture of the southern continental and the northern continental in late Paleozoic to early Mesozoic.

The crustal thickness beneath the Qaidam basin, a former Mesozoic block involved in the convergence and deformation system of India-Asia, has been well-constrained at $(52 \pm 2) \mathrm{km}$ (Teng, 1974; Lu and Chen, 1987, 1990; Cui et al, 1995, 1999; Zhao et al, 2003; Li et al, 2004b) in its central region and 58-61 km beneath its northern margin (Zhao et al, 2003). These thicknesses are approximately $10 \mathrm{~km}$ larger than those of adjacent blocks (both Tarim basin and Sichuan basin (Yangtze) have an average thickness of $45 \mathrm{~km}$ ) (Cui et al, 1996; Li et al, 2001). Beneath the Qilian Shan, the northern neighbor of the Qaidam basin, the crustal thickness is $70 \mathrm{~km}$ to $57 \mathrm{~km}$ with the Moho shallowing to the north and a $\sim 10 \mathrm{~km}$ south-face dipping beneath Golmud-Ejin Qi profile (Cui et al, 1995, 1999; Gao et al, 1995) that shows a notable contrast to the Hexi Corridor basin (North China Plate ) where Moho with a depth of $48 \sim 52 \mathrm{~km}$ extends smoothly (Figure 4).

\section{Steep variations in Moho depth un- der boundaries of terranes /blocks}

The Tibetan Moho features violent rise and fall topography from a $500 \mathrm{~km}$ fan-profile presented by Hirn et al (1984a) and Allegre et al (1984) in which 20 km off- set was postulated beneath the IYS and the other sutures. But a 300-km in-line profile (DSS profile 16 in Figure 1) across IYS to the west shows the crust only gets moderately shallower $\sim 5 \mathrm{~km}$ at the northern side of the IYS. The BNS is thought to have formed during the late Jurassic-Early Cretaceous as a consequence of the collision between the Lhasa and Qiangtang block/terrane. 2-3 km shallow of the Moho does indeed exist 25-50 $\mathrm{km}$ north of the surface trace of the BNS beneath the INDEPTH III profile (No.10 on Figure 1), contradicting the $20 \mathrm{~km}$ Moho offset proposed by Hirn et al (1984 a).

Moho variations beneath the JS are similar to those beneath the IYS and BNS, with a range of 5 to $10 \mathrm{~km}$ from DSS profiles (Vergne et al, 2002; Li et al, 2004a,b). The Moho under the southern boundary of the East Kunlun has not been stringently constrained, but several studies have shown it has only 7-10 km Moho offset relative to the northern boundary of the East Kunlun ( $\mathrm{Li}$ et al, 2004c, Zhao et al, 2003). Both the profiles along the northern margin fault of the Qaidam basin and across it verify that the fault stretches to a depth of 70 $\mathrm{km}$ (Cui et al, 1995; Wang et al, 2000; Zhao J M et al, 2001). The Qilian Shan is often considered the northeastern edge of the Tibetan plateau (Yin and Mark, 2000; Tapponnier et al, 2001). Along the geographical southern and northern fringe boundary of the Qilian Shan, there are a strike-slip fault (as SQS in Figure 1) with a dip-direction variation and a south-dipping up-thrust fault (as NQS in Figure 1). The NQS with a $5 \mathrm{~km}$ located step-uplift of the Moho extends through the whole crust from the surface into the top of upper mantle (Figure 4).

On the regional scale, steep variations in Moho are always seen under the boundaries of the blocks (sutures) or in their vicinity though the scale/magnitude of the Moho offset from the in-line profile is far less than the 10-20 km proposed by Hirn et al (1984) previously. Furthermore, if the crustal structure is imaged with variation of $v_{\mathrm{P}} / v_{\mathrm{S}}$ from a joint receiver function and DSS approach across the Himalaya and Tibet, the Moho appears much more complex (Galvé et al, 2002b). The Moho remains relatively stable in the block interior but always features steep variations near the boundaries of the blocks (such as IYS, BNS, JS, NKS, SQS and NQS), which indicates boundaries of accreted blocks can remain in the deep or can be reactivated by continental collision. Therefore, the plateau accretion hypothesis incorporating building up of Mesozoic terranes has actually been supported by these observations. At the same 
time this also hints that the trace of the sharp rise of the Moho depth related to the previous collision will gradually be erased if it is not reactivated. As we seen in Figures 2, 3 and 4, Moho offsets produced by previous collisions appear less than those produced later.

\section{Crustal structure characteristics and lateral variation}

The crustal structure of the Tibetan plateau is illuminated in a velocity-depth contour cross section striking SW-NE through the Himalayas to the Qaidam basin (Figure 5).

\subsection{Vertical crustal structure}

The crustal structure of the plateau is representative (typical) of continent crust with a thickness of $60+\mathrm{km}$ on average and a vertical 2-divided structural pattern.

The upper crust with a thickness of $30-40 \mathrm{~km}$ include a gradual increasing velocity layer of sedimentary and constant velocity layer of crystallize rock and generally show the most significant lateral variation correlated with evolution process of the blocks composed of the plateau Mesozoic to Neozoic.

A velocity-reversed layer has variable location at the bottom or interior of the upper crust at a depth of $(20 \pm 5) \mathrm{km}$ beneath the surface with a thickness of 5-8 $\mathrm{km}$, velocity of $5.6-5.8 \mathrm{~km} / \mathrm{s}$, and local thickening beneath southern Tibet (south of IYS) and northern Tibet (north of JS). Between the IYS and JS, the crust of central Tibet from the surface down to a depth of $40 \mathrm{~km}$ has been filled up with extensive lower velocities.

A lower velocity layer in the middle crust and a gradually increasing velocity zone in the lower crust is considered to be a detachment zone (Main Himalayan thrust) beneath high and Tethyan Himalaya (Zhao et al, 1993) and an indicator of decoupled upper and lower crust in the northern part of Tibetan plateau. A broad lower-velocity area in the middle crust of the Lhasa block is interpreted as a layer of partial melting (Nelson et al, 1996; Makovsky et al, 1996). There is evidence of the lower velocity disappearing or local thinning, reflecting the complexity of continental crust in a young orogen. The crust-mantle transform zone is not ubiquitous beneath the plateau profiles.

The lower crust shows more structural complexity due to non-coincident thickening. It is usually thick ( $\sim 40$ $\mathrm{km}$ ), with a constant velocity and a simple structure, but sometimes it can be modeled as a gradually increasing velocity layer such as the Lhasa block and Bayan Har block. In contrast with the upper crust, the lower crust seems to be impacted to a greater extent by present day tectonic activity and temperatures caused by continent-continent collision in the Himalaya and southern Tibet and intra-continent underthrust beneath the east Kunlun orogen.

\subsection{Lateral variation of crustal structure}

On the scale of whole crust, the northeast profiles reveal significant lateral variation in crustal structure (Zeng et al, 1998). The typical "double-crust" pattern beneath the Himalaya and southern Tibet actually does not appear in the extensive region of central and northern Tibet even though where the crustal thickness reaches double that of east China $(30 \sim 40 \mathrm{~km})$. Passive source seismic data may suggest the top of the Indian upper mantle underthrust the Tibetan Plateau a long distance, but has no available active source data supports Indian crust also underthrust over IYS (Hauck et al, 1998). So "double-crust" may be a special case of the crust replying the collision between India and Asia.

The lateral variation of upper crust of the Tibetan plateau is considerable and reasonable to relate to the evolution during the Mesozoic to Cenozoic at that period the successive ranges and intermountain basins formed (Chang et al, 1982).

The upper crust of the Himalayan terrane can be characterized as 3 rock pieces or layers separated by 3 southward thrusting faults that converge in the lower velocity MHT. This region may have originated as a continent-ocean (Indian plate-Tethys) margin fed by sediments before the collision of the Indian and Eurasian plates (Li, 1995). The Lhasa block was considered as split from the Gondwana continent and accreted at the margin of Asia as the Tethys opened. The Gangdese region, at the northern side of IYS, is actually the southern part of the Lhasa block, as is apparent from a high velocity area related to uplift and erosion process after collision. Sequentially to the north, a lower velocity area extending for $100 \mathrm{~km}$ around the BNS covered the Northern part of the Lhasa block and the southern part of Qiang Tang block, as shown in Figure 5. The Qiangtang block with a flat topography and thick sedimentary layers actually forms the center of the Tibetan plateau. The Jurassic Jinsha suture divides the Bayan Har block, also called Songpan-Garze Terrane, from the Qiangtang block. The Bayan Har block is considered to have originated as a continent-ocean margin with a 5 to 10 $\mathrm{km}$ thick cover of Triassic flysch. The Kunlun-Qaidam block, separated from the Bayan Har block by the Triassic 


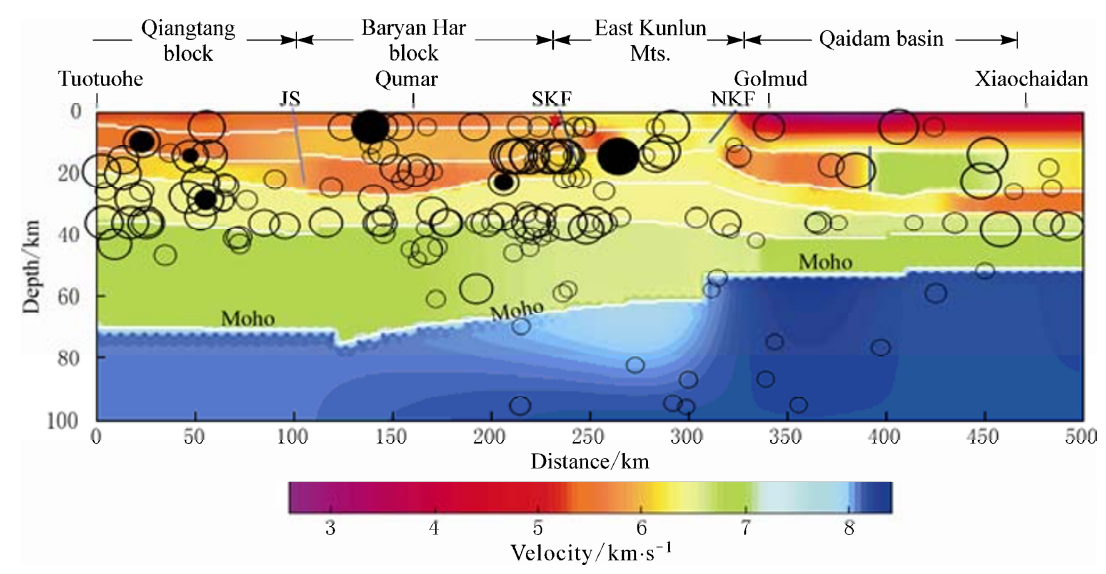

Figure 3 The velocity-depth section beneath the northeastern region of Tibetan plateau. Js: Jinsha river suture; SKF: the southern edge fault of East Kunlun; NKF: the northern edge thrust fault of East Kunlun; Open circles denote the epicenters during 1964-2003, while solid circles represent $M_{\mathrm{S}}>6.0$ earthquake epicenters during 1980-2003 (projection along attitude, data is from www.iris.washington.edu), the location of $M_{\mathrm{S}} 8.1$ earthquake in 2001 is marked with a star near SKF beneath surface. The color scale is $\mathrm{P}$ wave velocity.

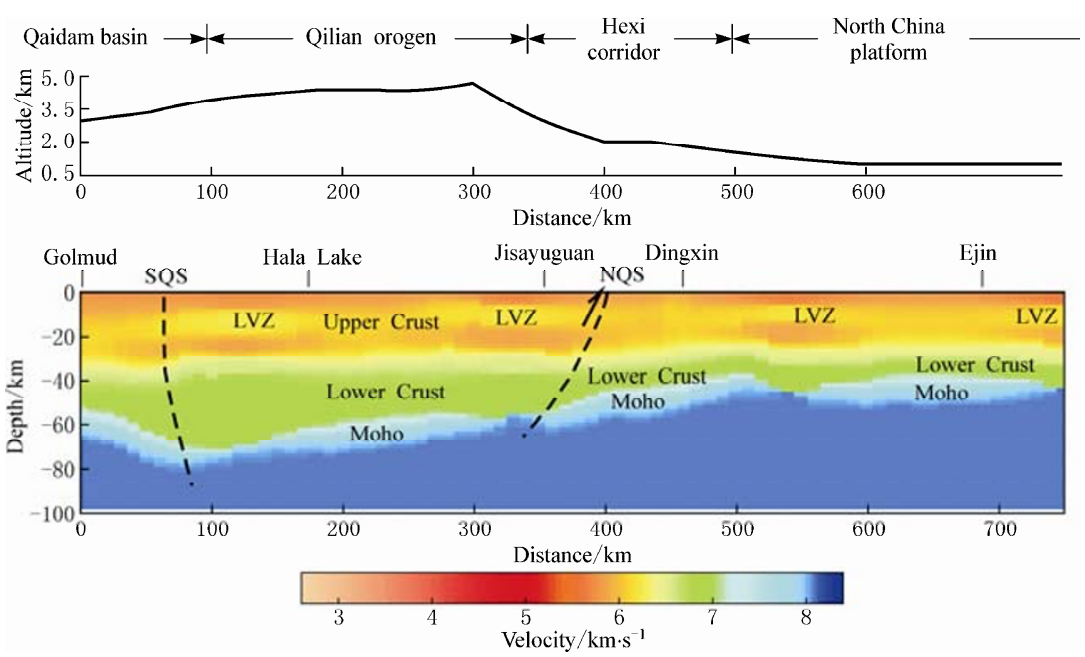

Figure 4 Crustal structure across the Qilian Shan to the Hexi corridor (North China) (Cui et al, 1995). SQS: Southern fault of Qilian Shan; NQS: Northern fault of Qilian Shan.

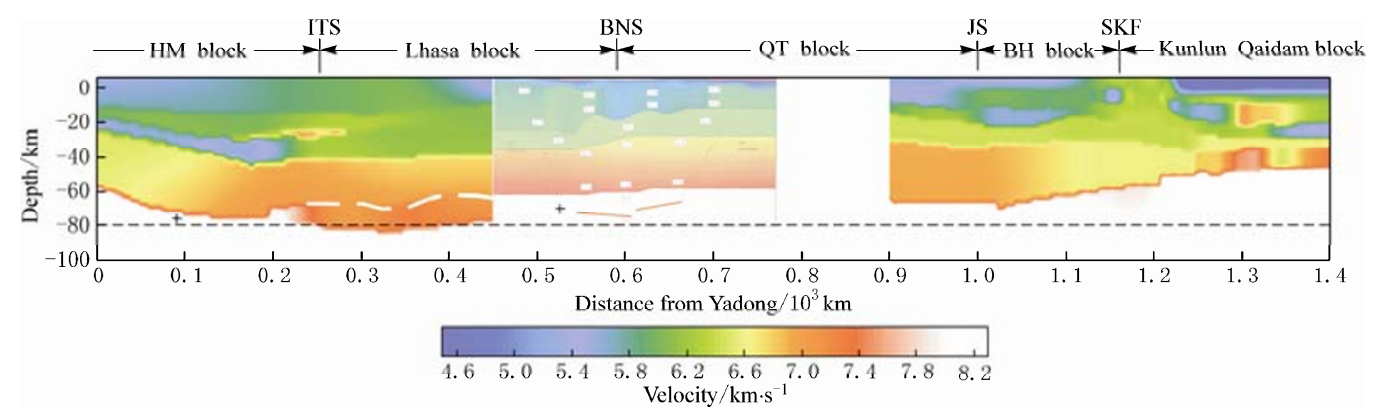

Figure 5 A P-wave velocity section across the Tibetan plateau. HM: Himalayan; QT: Qiangtan; BH: Bayanhar; ITS (equal to IYS): Indus-Tsangpo Suture; SKF: Southern Kunlun fault; BNS: Bangong-Nujiang suture; JS: Jinsha suture; White gaps are areas with no data coverage. The two "+"symbol indicate Moho depth of the cross profile 2, 3 (see Figure 1). The red lines appeared under BNS represent the Moho depth in the west $200 \mathrm{~km}$ of this section. 
Kunlun suture, has a more complex structure with higher and lower velocity layers caused by earlier evolution processes.

The middle crust can be characterized by variations in thickness and velocity magnitude of the lower/reversed layer. Except for the extensive lower velocity layer in the middle crust of the Lhasa block, a 5 to $10 \mathrm{~km}$ thick lower velocity layer appears in the Tibetan crust. The appearance of the lower/reverse velocity layer is probably related to shear action and temperature rise after the collision.

Clear lateral variation is present in the lower crust between the blocks of the Tibetan Plateau. The Yadong-Golmud GGT depicts a reverse velocity structure at a depth of 38-78 km and a thickness of $40 \mathrm{~km}$ beneath the Tethyan Himalaya (Wu et al, 1991). A gradient zone was reported from a depth of $55 \mathrm{~km}$ beginning with a thickness of $20-30 \mathrm{~km}$ and an average velocity of $7.40 \mathrm{~km} / \mathrm{s}$. A similar phenomenon occurs in the lower crust of the East Kunlun, as described by Lu et al (1990). The gradient velocity layer (mixed layer of crust and mantle) usually accompanies strong shortening of the lower crust, but this combination is not confirmed anywhere beneath the Tibetan plateau.

\subsection{The velocity-depth rela tionship and its lateral variation}

The average crustal velocity of the Tibetan plateau ranges from $6.10 \mathrm{~km} / \mathrm{s}$ to $6.30 \mathrm{~km} / \mathrm{s}$, which is below the level of adjacent Tarim basin crust ( $\mathrm{Li}$ et al, 2001; Li, 2004; Zhao et al, 2001, 2003, 2006) and Sichuan basin crust (Cui et al, 1996) and indicates a felsic-to-intermediate crustal composition of continental type.

For crystallized crust, lateral variation of average velocity usually looks so small that it is not worth noticing in comparison with thickness variation. Naturally Himalayan terrane has moderate lateral velocity variations, as do the Bayan Har and East Kunlun terranes. Lateral variations are greater beneath the Lhasa and Qiangtang terranes, especially in the northern Lhasa and Qiangtang blocks. The lack of significant difference in mean velocity for the blocks seems to suggest that geometrical deformation (a geophysical process) is dominant in the process of the plateau uplift.

The Pn wave velocity at the top of the upper mantle in the Tethyan Himalaya is $8.2 \pm 0.2 \mathrm{~km} / \mathrm{s}$, near the global continental average. The Indian continent Pn velocity is $8.3 \mathrm{~km} / \mathrm{s}$ to $8.4 \mathrm{~km} / \mathrm{s}$, implying a normal top lid of upper mantle beneath the Tethyan Himalaya crust with predi- cate Indian lithospheric mantle inserted beneath the Southern Tibetan at a steep angle (Zhao et al, 2004).

Studies have not yet determined Pn in the interior of the plateau. Possible reasons for this include that the receiver were not far enough from the shotpoint for the huge thickness of Tibetan plateau or that the Moho discontinuity is too weak to generate a detectable Pn wave. Acquisition of the Pn wave group has become a key task of DSS surveys in the Tibetan plateau.

\section{Conclusions}

Although many mysteries remain, a preliminary geometric pattern of the crust across Tibetan plateau has been constructed from active source seismic profiles in the past several decades.

Results from active source seismic profiling yield an image of the crust shows a flat crust-mantle interface in central Tibet and northeastward or southwestward deepening in the Himalaya/southern Tibet and in central-northern Tibet, respectively.

The Moho interface is buried at the range of $60-80$ $\mathrm{km}$ on average and has steep ramps located roughly beneath first order topographic or geological boundaries. Such an image is compatible with the successive stacking/accretion of large crustal thrust wedges that would have grown northeastward.

Crustal deformation behaved quite differently in southern Tibet and northern Tibet. The deepest Moho in the vicinity of IYS and the crustal scale thrust beneath southern Tibet obtained by near vertical reflection profiles (Zhao et al, 1993; Brown et al, 1996; Zhao et al, 1997; Hauck et al, 1998; Mayakovsky et al, 1999) suggest strong dependence on collision and non-distributed deformation which is coincident with GPS data (Wang et al, 2001). Both the low normal $v_{\mathrm{P}} / v_{\mathrm{S}}$ ratio and the Moho stepwise rise fail to support significant partial melting in the middle-lower crust of the central-northern Tibet plateau but imply the regional gravity adjustment is in a dominant position far from the main collision zone.

It is notable that the crustal thickness of Tibet is double that of eastern China and 15-20 km larger than adjacent blocks. Evidently, convergence between India and Asia occurs differently in the southern and northern plateau. In the south there is at least $350 \mathrm{~km}$ shortening that was accommodated by underthrusting along the crustal scale MHT. Though underthrusting also probably occurred during the early period of collision in northern 
Tibet, current data shows no crustal scale detachment zone. Extensive high temperatures in the middle crust as well as high strains in the lower crust hint that continuous northward movement of the India plate was predominantly accommodated by lower crustal thickening as well as "strike-slip" and "crustal flow".

Furthermore, the Moho depth almost always varies steeply under the block's boundaries, which is consistent with the hypothesis of an embryonic plateau formed by accretion of former Cenozoic terranes. However, the $\sim 20 \mathrm{~km}$ order of Moho offsets has not been confirmed by any higher accurate seismic profiling (Zhao et al, 1997, 2001).

The weak geophysical signature of the BNS suggests that convergence has been accommodated perhaps partially through pure-shear thickening accompanied by removal of lower crustal material by lateral escape, likely via ductile flow. The continuous, south-dipping Moho with $\sim 7 \mathrm{~km}$ offset beneath the east Kunlun orogen and the large scale thrust faulting in the northern margin of the Qilian Shan are both unable to accommodate a convincing explanation for the Cenozoic collision along the IYS although it is acknowledged.

The extensive lower-velocity layer of the Tibetan Plateau undoubtedly plays an important role in explaining mechanisms of Tibetan plateau uplift. As in the crust of most continents, the well-constrained reverse or lower velocity layer in the middle crust in southern Tibet is considered a detachment zone (MHT). The velocity gradient zone in the lower crust is usually considered as an indicator of decoupled upper and lower crust (Mooney and Brocher, 1987, Christensen and Mooney, 1995). The broad lower-velocity area in the middle crust of the Lhasa block results in partially melting rocks filled with liquid minerals. The evidence of the lower-velocity disappears, and/or local thinning exhibits the complexity of the Tibetan continental crust. The crust-mantle transform zone is not seen in every profile acquired thus far.

Acknowledgements This paper was financed by the Ministry of Land and Resources of China (2004DKA20280-2-5), International Sciences and Technology cooperation (2006DFA21340), the special funds for Sciences and technology research of public welfare trades (200811021), the key innovation project for sciences and technology of Ministry of Land and Resources (1212010711813), the China Geology survey Bureau and resources land investigation project
(1212010611809), the Basic outlay of scientific research work from Ministry of Science and Technology of the People's Republic of China (J0803), the National Natural Science Foundation of China (40830316 and 40874045), SINOPPROBE-II and Open Fund (NO.GDL0603_) of Key Laboratory of Geo-detection (China University of Geosciences, Beijing), Ministry of Education".

\section{References}

Allegre C J, Coartillot V, Tapponnier P, Hirn A, Mattauer M, Coulon C, Jaeger $\mathrm{J} J$ and Achache J (1984). Structure and evolution of the Himalaya-Tibet orogenic belt. Nature 307(5): 17-22.

Brown L D, Zhao W J, Nelson K D, Hauck M, Alsdorf D, Ross A, Cogan M, Clark M, Liu X W and Che J K (1996). Bright spots, structure, and magmatism in southern Tibet from INDEPTH seismic reflection profiling. Science 274: 1 688-1 690.

Chang C F, Pan Y S, Zheng X L and Zhang X M (1982). The Geological Tectonics of Qinghai-Xizang (Tibet) Plateau. Science Press, Beijing.

Chen G Y and Zeng R S (1985). The difference of lithospheric structure between Himalayan mountain and Tibetan plateau from surface wave dispersion. Acta Geophysica Sinica 28(Suppl.): 161-173 (in Chinese with English abstract).

Christensen N I and Mooney W D (1995). Seismic velocity structure and composition of the continental crust: a global view. $J$ Geophys Res 100: 9 761-9 788 .

Cui Z Z, Chen J P and Wu L (1996). Deep crustal structure and tectonics of Huashixia-Jianyang profile. Geological Publish Houses, Beijing.

Cui Z Z, Li Q S, Meng L S and Guan Y (1999). Golmud-Ejin Qi Lithospherical Stucture and Deep Tectonic. Geological Publish Houses, Beijing (in Chinese).

Cui Z Z, Li Q S, Wu C D, Yin Z X and Liu H B (1995). The crustal and deep tectonics in Golmud-Ejin Qi GGT. Chinese J Geophys 38 (Suppl.): 15-28 (in Chinese with English abstract).

Ding Z F, Zeng R S, Wu T and Frances (1992). Pn velocity and Moho interface relief beneath Qinghai-Tibet Plateau. Acta Seismologica Sinica 14(Suppl. ): 592-599 (in Chinese with English abstract).

Galvé A, Hirn A, Jiang M, Gallart J, Voogd B, Lépine J C, Diaz J, Wang Y X and Qian H (2002a). Modes of raising northeastern Tibet probed by explosion seismology. Earth Planet Sci Lett 203: 35-43.

Galvé A, Sapin M, Hirn A, Diaz J, Laigle M and Gallart J (2002b). Complex images of Moho and Variation of $v_{\mathrm{p}} / v_{\mathrm{S}}$ across the Himalaya and South Tibet, from a joint receive-function and wide-angle-reflection approach. Geophys Res Lett 29(24): 351-354.

Gao R and Wu G. J (1995). Geophysical model and geodynamic process of Yadong-Golmud geoscience transect on Qinghai-Tibet plateau. Journal of Changchun University of Earth Sciences 25(3): 241-250 (in Chinese with English abstract).

Gao R, Liu H, Li Q, Li P, Yao P and Huang D (2000a). A deep seismic reflection profile across Altyn fault belt. In: Earth Science Frontiers ed. The 15th Himalaya-Karakorum-Tibet Workshop Abstract Volume, 7(Suppl.): 205.

Gao R, Lu Z W, Li Q S, Guan Y, Zhang J S, He R Z and Huang L Y (2005b). Geophysical survey and geodynamic study of crust and upper mantle in the Qinghai-Tibet Plateau. Episodes 28(4): 263-273.

Gao R, Huang D, Lu D, Li Y K, Kuang C Y, Li Q S, Feng R J and Guan Y (2000b). Deep seismic reflection profile across the ncture zone between the Tarim basin and the West Kunlun Mountains. Chinese Science Bulletin 45(17): 2 281-2 286.

Gao R, Ma Y S and Zhu X. (2005a). The lithospheric structures of the Songpan block in the northeastern Tibetan Plateau-revelation from investigation of the deep seismic profile: Geology Alpine, 20th Himalayan-Karakoruam-Tibet Workshop Special extended abstracts, Aussois France, 44. 
Griot D A, Montagner J P and Tapponnier P. (1998). Phase velocity structure from Rayleigh and Love waves in Tibet and its neighboring regions. $J$ Geophys Res 103: 21 215-21 232.

Haines S S, Klemperer S L, Larry Brown, Guo J R, Mechie J, Meissner R, Ross A and Zhao W J (2003). INDEPTH-III seismic data: From surface observations to deep crustal process in Tibet. Tectonics 22 (1): 1-18.

Hauck M L, Nelson K D, Brown L D, Zhao W J and Ross R (1998). Crustal structure of the Himalaya orogen at $\sim 90^{\circ}$ east longitude from Project INDEPTH deep reflection profile. Tectonics 17(4): 481-500.

Hirn A, Nercessian A, Sapin M, Jobert G, Xu Z X, Gao E Y, Lu D Y and Teng J W (1984a). Lhasa block and bordering sutures, a continuation of a $500-\mathrm{km}$ Moho traverse through Tibet. Nature 307(5946): 25-27.

Hirn A, Lepine J C, Jobert T G, Sapin M, Wittlinger G, Xu Z X, Gao E Y, Wang X J, Teng J W, Xiong S B, Pandey M R and Talte J M (1984b). Crust structure and variability of the Himalayan border of Tibet. Nature 307(5946): 23-25.

Institute of Geophysics, Chinese Academy of Sciecces (1981). Explosion seismic study for velocity distribution and structure of the crust and upper mantle from Damxung to Yadong of Xizang Plateau. Acta Geophysica Sinica 24(2): 155-170 (in Chinese with English abstract).

Kind R, Ni J, Zhao W, Wu J, Yuan X, Zhao L, Sandvol E, Reese C, Nabelek J and Hearn $T$ (1996). Evidence from earthquake data for a partially molten crustal layer in southern Tibet. Science 274: 1 692-1 694.

Kind R, Yuan X, Saul J, Nelson D, Sobolev S V, Mechie J, Zhao W, Kosarev G., Ni J, Achauer U and Jiang M (2002). Seismic images of crust and upper mantle beneath Tibet: evidence for Eurasian plate subduction. Science 298: 1 219-1 221.

Li Q S, Gao R, Lu D Y, Li J W, Fan J Y, Zhang Z Y, Liu W, Li Y K, Yan Q R, Li D X and Wide angle team (2002). Tarim underthrust beneath western Kunlun-Evidences from wide-angle seismic sounding. Journal of Asia Earth Sciences 20: 247-253.

Li Q S, Gao R, Lu D Y, Li J W, Fan J Y, Xiong X M, Zhang Z Y, Liu W, Li Y K, Yan Q R and Li D X (2001). An explosive seismic sounding profile across the transition zone between west Kunlun Mts. and Tarim basin. Science in China (Series D) 44(7): 666-672.

Li Q S, Peng S P and Gao R (2004a). A review on the Moho discontinuity beneath the Tibetan Plateau. Geological Review 50(6): 598-612 (in Chinese with English abstract).

Li Q S, Peng S P, Gao R, Guan Y and Fan J Y (2004b). Deep tectonic background of the $M_{\mathrm{S}} 8.1$ earthquake in the east Kunlun. Acta Geoscientica Sinica 25(1): 11-16 (in Chinese with English abstract).

Li Q S (2004c). The seismology study of lithosphere structure of continental-continental collision zone in Tibetan Plateau. Thesis for the PH. Doctorate of China University of Mining and Technology, Beijing.

Li S L, Zhang X K and Zhang C K (2002). A preliminary study on the crustal velocity structure of Maqin-Lanzhou-Jingbian by means of deep seismic sounding profile. Chinese J Geophys 45(2): 210-217 (in Chinese with English abstract).

Li T D (1995). The uplifting process and mechanism of the Qinghai-Tibet Plateau Acta Geoscientia Sinica (1): 1-9 (in Chinese with English abstract).

Liu H B, Kong X R, Gao R and Li Q S. (2004). Deep seismic probe of the crust and upper mantle structure across the western part of Yalung Zangbo Suture. In: Zheng D, Yao T D et al eds. Uplifting of Tibetan Plateau With its Environmental Effects. Science Press, Beijing, 60-65 (in Chinese with English abstract).

Lu D Y and Chen J P (1987). Deep Structure of the crust in Tuotuohe-Golmud region of north Qinghai-Xizang Plateau. Geology Review 33(2): 122-128.

Lu D Y, Huang L Y, Chen J P, Li X P, Hu A B, Wang Y Z, Wang Z C, Liu W T and Zhang Z Y (1990). Structural model and velocity dispersion characteristics of the crust and upper mantle in Tuotuohe-Golmud region of north Qinghai-Xizang Plateau. In: Geophysical Memoir on Xizang-Qinghai Plateau. China Geological Publishing House, Beijing, 51-62.

Lü Q T, Jiang M and Ma K Y (1996). 3-D travel time tomography inversion and the deep structure of southern Tibet. Acta Seismologica Sinica 18(4): 451-459 (in Chinese with English abstract).

Makovsky Y, Klempere S L, Ratschbacher L, Brown, L D, Li M, Zhao W J and Meng F L. (1996). INDEPTH wide-angle reflection observation of
P-wave-to-S-wave conversion from crustal bright spots in Tibet. Science 274: 1 690-1 691.

Mayakovsky Y, Klemperer S L, Ratschbacher and Alsdorf D (1999). Midcrustal reflector on INDEPTH wide-angle profiling: An ophiolitic slab beneath the India-Asia suture in southern Tibet? Tectonics 18(5): 793-808.

Mooney W D and Brocher T M (1987). Coincident seismic reflection/refraction studies of the continent lithosphere. Rev Geophys 25: 723-742.

Nelson K D, Zhao W J, Brown L D, Kuo J, Che J K, Liu X W, Klemperer S L, Marovsky Y, Meissner R, Mechie J, Kind R, Wenzel F, Ni J, Nabelek J, Chen L S, Tan H D, Wei W B, Jones A G, Booker J, Unsworth M, Kidd W, Hauck M, Alsdorf D, Ross A, Cogan M, Wu C D, Sandvol E and Edwards M (1996). Partially molten middle crust beneath Southern Tibet: Synthesis of project INDEPTH results. Science 274: 1 684-1 688.

Pelkum S, Monsalve G, Sheehan A, Pandey M R, Sapkota S, Bilham R and Wu F (2005). Imaging the Indian subcontinent beneath the Himalaya. Nature 435: $1222-1225$.

Ross A, Brown L, Passakorn P, Nelson K D, Klemperer S, Haines S, Zhao W J and Guo J R (2004). Deep reflection surveying in central Tibet: lower-crustal layering and crustal flow. Geophys J Int 156: 115-128.

Sapin M, Wang X J, Hirn A and Xu Z X (1985). A seismic structure sounding in the crust of Lhasa block, Tibet. Ann Geophys 3: 637-648.

Tapponnier P, Xu Z Q, Roger F, Meyer B, Arnaud N, Wittlinger G, Yang J S (2001). Oblique stepwise rise and Growth of the Tibet Plateau. Science 294(23): 1 671-1 677.

Teng J W (1974). Deep reflected waves and the structure of the earth crust of the eastern part of Qaidam basin. Acta Geophysica Sinica 17(2): 121-134 (in Chinese with English abstract).

Teng J W, Xiong S B, Yin Z X, Xu Z X, Wang X T and Lu D Y (1983). Structure of the crust and upper mantle pattern and velocity distributional characteristics in the Northern Himalayan mountain region. Acta Geophysica Sinica 26(6): 525-540 (in Chinese with English abstract).

Teng J W, Yin Z X and Xiong S B (1985). Crustal structure and velocity distribution beneath Selin Co-Peng Co-Na Qu-Suo County region in northern Xizang Plateau. Acta Geophysica Sinica 28(Suppl.): 28-42 (in Chinese with English abstract).

Vergne J, Wittlinger G, Qian H, Tapponnier P, Poupinet G, Jiang M, Herquel G and Paul A (2002). Seismic evidence for stepwise thickening of the crust across the NE Tibetan Plateau. Earth Planet Sci Lett 203: 25-33.

Wang C Y, Han W B, Wu J P, Lou H and Bai Z M (2003a). Crustal structure beneath the Songpan-Garze orogenic belt. Acta Seismologica Sinica 16(3): 237-250.

Wang C Y, Wu J P and Lou H (2003b). Crustal P-wave velocity structure in western Sichuan and eastern Tibet. Science in China (Series D) 33(Suppl.): 181-189 (in Chinese with English abstract).

Wang Y X and Qian H (2000). Study of crustal velocity structure in the east Qinghai. Earth Science Frontiers 7(4): 568-579 (in Chinese with English abstract).

Wittlinger G, Tapponnier P, Poupinet G, Jiang M, Shi D, Herquel G and Masson F (1998). Tomographic evidence for Localized lithospheric shear along the Altyn Tagh fault. Science 282: 74-76.

Wu G J, Gao R, Yu Q F, Cheng Q Y, Meng L S, Dong X B, Cui Z Z, Yin Z X, Shen X J and Zhou Y X (1991). Intergrated investigations of the Qinghai-Tibet Plateau along the Yadong-Golmud geoscience transect. Acta Geophysica Sinica 34(5): 552-562 (in Chinese with English abstract).

Wu J P, Ming Y H, Ye T L and Zeng R S (1998). Upper mantle velocity structure in the Qinghai-Xizang Plateau from inversion of body waveforms. Acta Geophysica Sinica 41(Suppl.): 15-25 (in Chinese with English abstract).

Wu Q J and Zeng R S (1998). The crustal structure of Qinghai-Xizang Plateau inferred from broadband teleseismic waveform. Acta Geophysica Sinica 41(5): 669-679 (in Chinese with English abstract).

Wu X Z, Wu C L, Lu J and Wu J (1995). Research on the fine crustal structure of the northern Qilian-Hexi Corridor by deep seismic reflection. Chinese $J$ Geophys 38(Suppl.): 29-35 (in Chinese with English abstract).

Xiong S B and Liu H B (1997). Crustal structure in western Tibetan Plateau. Chinese Science Bulletin 42(8): 665-668.

Xiong S B, Teng J W and Yin Z X (1985). The thickness of the crust and undu- 
lation of discontinuity in Xizang (Tibet) Plateau. Acta Geophysica Sinica 28(Suppl.): 16-27 (in Chinese with English abstract).

Xu X Z, Qi X F, Yang C L and Dang S J (1993). Results of man-made explosion seismic sounding from Huashixia (in Qinghai) to Aksay (in Gansu). In: Annual of the Chinese Geophysical Society. Seismological Press, Beijing, 80 .

Yin A and Mark H T (2000). Geologic evolution of the Himalayan-Tibetan Orogen. Annu Earth Planet Sci 28: 211-280.

Yuan X H, Ni J, Kind R, Mechie J and Sandvol E (1997). Lithspheric and upper mantle structure of southern Tibet from a seismological passive source experiment. J Geophys Res 102(B12): 27 491-27 500.

Zeng R S and Gan R J (1961). Reflected waves from crustal interface in western Qaidam Basin. Acta Geophysica Sinica 10(1): 120-125 (in Chinese with English abstract).

Zeng R S, Ding Z F and Wu Q J (1998). The crustal structure from Himalaya to Qilian and its implications for continent-continent collision process. Chinese J Geophys 41(1): 49-60 (in Chinese with English abstract).

Zeng R S, Ding Z F, Wu Q J and Wu J P (2000). Seismological evidence for the multiple income crustal subductions in Himalayas and southern Tibet. Chinese J Geophys 43(6): 780-797 (in Chinese with English abstract).

Wang Q, Zhang P Z, Freymueller J T, Billham R, Larson M K, Lai X, You X, Niu Z J, Wu j C, Li Y X, Liu J N, Yang Z Q and Chen Q Z (2001). Present-Day Crustal Deformation in China Constrained by Global Positioning System Measuremments. Science 294: 574-577.

Zhang X K, Jia S X, Zhao J R, Zhang C K, Yang J, Wang F Y, Zhang J S, Liu B. F, Sun G W and Pan S Z (2008). Crustal structures beneath West Qinling East Kunlun orogen and its adjacent area — Results of wide angle seismic reflection and refraction experiment. Chinese J Geophys 51(2): 439-450 (in Chinese with English abstract).

Zhang Z J, Wang G J and Sun R M (2002a). P-wave structure along $1100 \mathrm{~km}$ long wide-angle seismic profile in the eastern Tibet. AGU, Japan.

Zhang Z J, Li Y K, Wang G J, Teng J W, Klemplerer S, Li J W, Fan J Y and Chen Y (2001). E-W crustal structure under the northern Tibet and 'down-bowing' Moho under the northern Tibet revealed by wide angle seismic profile. Science in China (Series D) 31(11): 881-888 (in Chinese with English abstract).
Zhang Z J, Teng J W, Li Y K, Klemperer S and Yang L Q (2002b). Crustal velocity structure and eastward escaping of crustal material in the southern Tibet. Science in China (Series D) 32(10): 793-798 (in Chinese with English abstract).

Zhao J, Mooney W D, Zhang X, Li Z, Jin Z and Okaya N (2006). Crustal structure across the Altyn Tagh Range at the northern margin of the Tibetan Plateau and tectonic implications. Earth Planet Sci Lett 241: $804-814$.

Zhao J M, Zhang X K, Wang S X, Lu B, Zhang J and Lu M A (2001). The lithospheric structure and dynamic process of the Junggar Basin, the Tianshan Orogenic Belt, the Tarim Basin, the Altun Orogenic Belt, the Qaidam Basin, and the Kunlun Orogenic Belt (northern margin). In: Chinese Geophysical Society ed. Annual of the Chinese Geophysical Society, 13.

Zhao J M, Zhang X K, Deng H Z and Zhang J (2003). Q value structure of the upper crust along the profile from Baicheng to Da Qaidam. Chinese $J$ Geophys 46(4): 503-509 (in Chinese with English abstract).

Zhao W J, Mechie J, Brown L D, Guo J, Haines S, Hearn T, Klemperer S L, Ma Y S, Meissner R, Nelson K D, Ni J F, Pananont P, Rapine R, Ross A and Saul J (2001). Crustal structure of central Tibet as derived from INDEPTH wide-angle seismic data. Geophys J Int 145: 486-498.

Zhao W J, Nelson K D and Meissner R (1997). Advances of INDEPTH-A deep profiling study in Tibet and the Himalayas. Episodes 20(4): 266-272

Zhao W J, Nelson K D and Project INDEPTH Team (1993). Deep seismic reflection evidence for continental underthrusting beneath southern Tibet. Nature 366(9): 557-559.

Zhao W J, Xue G Q, Zhao X, Wu Z H, Shi D N, Liu K, Jiang W, Xiong J Y and INDEPTH Team (2004). Seismic imaging of the subducting Indian lithosphere beneath northern Tibet. Acta Geoscientia Sinica 25(1): 1-10 (in Chinese with English abstract).

Zhu L P and Helmberger D V (1998). Moho offset across the northern margin of the Tibetan Plateau. Science 281: 1 170-1 172.

Zhuang Z, Fu Z W, Lu Z L, Hu J F, Song Z H, Chen G Y, An C Q and Chen L $H$ (1992). 3-D shear velocity model of crust and upper mantle beneath the Tibetan Plateau and its adjacent regions. Acta Geophysica Sinica 35(6): 694-709 (in Chinese with English abstract). 